\title{
LOS COMUNES EN FEMENINO. CUERPO $Y$ PODER ANTE LA EXPROPIACIÓN DE LAS ECONOMÍAS PARA LA VIDA ${ }^{1}$
}

\section{THE COMMONS IN FEMININE. BODY AND POWER FACING THE EXPROPRIATION OF THE ECONOMIES FOR LIFE}

\author{
Natalia Quiroga Díaz ${ }^{2}$ \\ Verónica Gago ${ }^{3}$
}

\begin{abstract}
Resumen
Retomamos la perspectiva de las feministas Federici (2010), y su investigación sobre el rol que jugó la caza de brujas y la expropiación de saberes y cuerpos femeninos en los inicios del capitalismo moderno; los trabajos de Gutiérrez (2013) y de Segato (2010), quienes reflexionan en América Latina sobre la explotación de lo común y el encapsulamiento del cuidado de la vida como algo privado y femenino, para pensar, en clave del presente, las nuevas modalidades en que esa expropiación se repite y se diferencia. También discutiremos la fase actual de acumulación capitalista y la subsunción de nuevos territorios y recursos comunes, analizando cómo estos nuevos cercamientos se ciernen sobre los ámbitos de la reproducción social y sobre los cuerpos y lugares de poder de las mujeres en particular. En contrapunto situaremos la crisis de 2001 en Argentina como un proceso de comunitarización de recursos sociales a partir de mecanismos de gestión popular.
\end{abstract}

Recibido el 23 de julio del 2013. Reenviado el 10 de febrero del 2014. Aceptado el 17 de febrero del 2014. Publicado el 19 de mayo del 2014.

doi: http://dx.doi.org/10.15359/eys.19-45.1

${ }^{1}$ Una versión abreviada de este artículo fue presentada como ponencia en una de las sesiones plenarias de la XII Conferencia Internacional Karl Polanyi, celebrada en Argentina, en la Universidad Nacional de General Sarmiento.

2 Investigadora docente, Instituto del Conurbano-Universidad Nacional de General Sarmiento-Argentina. Economista de la Universidad Nacional de Colombia, Especialista en Desarrollo Regional de la Universidad de los Andes, Magister en Economía Social de la Universidad Nacional de General Sarmiento, Doctoranda en Antropología Social Universidad Nacional de San Martin. Correo electrónico:nataliaquirogadiaz@gmail.com

3 Doctora en Ciencias Sociales de la Universidad de Buenos Aires (UBA)-Argentina. Docente en la Facultad de Ciencias Sociales (UBA). Becaria postdoctoral del CONICET (Consejo Nacional de Investigaciones Científicas y Técnicas). Correo electrónico: veronicagago@hotmail.com

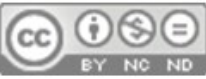


Palabras clave: Economía social; economía popular; mujeres; bienes comunes; crisis; acumulación; feminismo.

\begin{abstract}
The authors take the perspective of feminist Federici (2010) and her work on the role played by the witch hunt and the expropriation of knowledge and the female body in the initial stages of modern capitalism, as well as the perspective of feminists Gutiérrez (2013) and Segato (2010), who reflect on the Latin American exploitation of the commons and the enclosure of an economy oriented towards the care of life as something private and feminine, in order to find how the new current expropriation modalities are repeated or show differences. The authors will also discuss the current phase of capitalist accumulation and the subsumption of new common territories and resources and analyze how new enclosures point to social reproduction, in particular women's bodies and areas of power. As a comparison, the 2001 Argentine crisis will be used as an example of a communitisation process of social resources based on popular management mechanisms.
\end{abstract}

Keywords: Social economy; popular economy; women; common goods; crisis; accumulation; feminism.

En el análisis de la constitución del capitalismo, Marx (2005) analiza el lugar de los cercamientos (enclosures) y expropiaciones, para lo cual formula el concepto de "acumulación originaria". Para comprender los inicios del modo de producción capitalista, Polanyi (2003) mostró el cercamiento de las tierras comunes y la mercantilización del trabajo -bajo la forma de fuerza de trabajo- como condiciones fundamentales para el desarrollo de un sistema de producción basado en la violencia y la expoliación.

Sin embargo, estas perspectivas ignoran (o desestiman) el lugar diferencial que conllevó este proceso para las mujeres, como lo han señalado trabajos clásicos que han criticado la mirada androcéntrica en Marx (2005) y Polanyi (2003) y, desde la teoría feminista, se han propuesto análisis que muestran la opresión más allá de las relaciones de clase y de la mercantilización del trabajo. Si bien excede los propósitos de este texto, no podemos dejar de mencionar el trabajo de autoras feministas de diversas tradiciones, que tempranamente han mostrado las implicancias particulares que, para las mujeres, tiene el modo de producción capitalista.

En la década de los setenta, se aborda un prolífico debate sobre las implicaciones del trabajo doméstico en el modo de producción como un campo desestimado por la teoría económica en general y en particular por los estudios marxistas. Reseñamos algunos de los trabajos clásicos que ilustran este debate, así como trabajos contemporáneos que muestran la pertinencia que sigue teniendo (Benería y Roldan, 1992; Butler, 2000; Delphy, 1977; Federici, 2012; Folbre, 1982; Gardiner, 1975; Hartmann, 1981; Humphries, 1977; James y Dalla, 1977; Molyneux, 1970, Nicole-Claude, 1991). En la crítica feminista

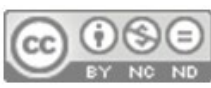


a Polanyi (2003) se abordan las implicaciones de la creación de las mercancías ficticias: tierra y trabajo para las mujeres, así como las limitaciones de entender las crisis como fruto de un conflicto de doble dirección entre la mercantilización y la protección social (Benería, 1999, 2005 y Fraser, 2012).

De forma más reciente, Federici (2010) retoma el concepto de acumulación originaria, mostrando su actualidad y la manera en la que sigue siendo un elemento central para la reproducción del sistema capitalista.

En este artículo relevamos el trabajo de Federici (2010), para poner de relieve la explotación femenina ausente; nos interesa, sobre todo, destacar su carácter inmanente a la llamada acumulación originaria, señalando la forma particular en que el capitalismo requirió el disciplinamiento y la apropiación del cuerpo de las mujeres, en simultáneo con la erosión de sus lugares de poder y de reconocimiento social.

Tomando como base esta línea de investigación histórica, este trabajo reflexiona sobre la "actualidad" de la acumulación originaria a partir de un eje conceptual: la manera en que el cercamiento de los bienes comunes sigue siendo un instrumento para la expansión del capital en el presente. En particular, argumentamos sobre las formas en que el sistema capitalista, a partir del predominio presente de su forma financiera (Chesnais, 2001; Marazzi, 2009), sigue ensanchándose a partir de la subsunción de nuevos territorios y recursos comunes (materiales e inmateriales). Pretendemos, de este modo, analizar cómo los nuevos cercamientos se ciernen -como diferencia y repetición-sobre los ámbitos de la reproducción social y sobre los cuerpos y lugares de poder de las mujeres en particular. Como contrapunto de este proceso, situaremos, paradójicamente, el momento de crisis de 2001 en Argentina, al cual señalaremos como momento para el des-cercamiento en un sentido preciso: como proceso breve e intenso de "feminización" de la economía y de comunitarización-o puesta en común- de recursos sociales, a partir de mecanismos de gestión popular que pusieron en marcha modalidades de reapropiación de bienes y servicios, que contribuyeron a una desmercantilización de la reproducción en una coyuntura extremadamente singular.

\section{La constitución del capitalismo revisitada}

Marx (2005) detalla la forma en que las comunidades campesinas fueron expropiadas de sus tierras y una serie de bienes comunes fueron convertidos en propiedad privada. Este proceso, llamado "acumulación originaria", muestra la manera en que la privatización de los medios de producción es un elemento central en la configuración de masas de seres humanos despojados, violentamente, de su forma de vida y obligados, por la pobreza, a vender su trabajo como proletarios libres.

El concepto de acumulación originaria es retomado por Harvey (2003), desplazando temporalmente esta misma noción para pensar su contemporaneidad: 
Una reevaluación general del papel continuo y persistente de las prácticas depredadoras de la acumulación "primitiva" u "originaria" en la amplia geografía histórica de la acumulación de capital es, por lo tanto, muy necesaria, como han observado recientemente varios autores. Dado que no parece muy adecuado llamar "primitivo" u "originario" a un proceso que se halla vigente y se está desarrollando en la actualidad, en lo que sigue sustituiré estos términos por el concepto de "acumulación por desposesión". (2003, p. 116)

El capitalismo nunca ha dejado de apelar a la violencia, al saqueo, al despojo y al desplazamiento. Plantea Harvey (2003) que no se trata de procesos incidentales: por el contrario, son inherentes a la necesidad permanente de expansión del mercado en el modo de producción capitalista. La desposesión de los bienes comunes materiales e inmateriales es un proceso permanente que salvaguarda el sistema en sus crisis y sostiene las condiciones de acumulación siempre crecientes.

En el análisis de los orígenes del capitalismo, Polanyi (2003) en La gran transformación muestra cómo su constitución solo fue posible mediante una profunda violencia social e institucional. Señala, como factores principales, la coerción de la ley, la servidumbre parroquial en Inglaterra, el rigor del trabajo bajo coacción en el continente europeo y en la América de comienzos de la época industrial. Estos factores fueron definitivos en la constitución de condiciones previas, para que las personas accedieran a la venta de sí mismas, bajo la forma de fuerza de trabajo. Sin embargo, es la instalación de la amenaza del hambre como amenaza de muerte la que, finalmente, obliga a este cambio de vida en términos masivos. Polanyi (2003), expone lo siguiente:

Era preciso destruir la sociedad orgánica que rechazaba la posibilidad de que los individuos muriesen de hambre; si se quieren proteger los intereses comunes puestos en peligro por ese sistema, se ha de recurrir necesariamente a fuerzas exteriores al propio sistema de mercado. (p. 270)

Acuñado como concepto, la "gran transformación" con la que el autor -nacido húngaro y nacionalizado inglés- tituló su obra, refería a la pretensión liberal de que los mercados funcionaran de manera autorregulada. Tal "utopía" fue efectiva, durante el siglo XIX y principios del XX; sin embargo, su colapso fue el inicio de otra "gran transformación": el advenimiento de la guerra, la depresión económica y el fascismo.

En esa perspectiva, Moulier-Boutang (2006) propone conceptualizar las mutaciones ocurridas en el trabajo asalariado a partir de la década de 1970, con ese mismo rótulo: como una nueva gran transformación. De modo que el concepto polanyiano puede referirse a un doble uso: como indicador de rupturas temporales, por un lado; pero, por

\footnotetext{
${ }^{4}$ Si bien, este trabajo no tiene el objetivo de presentar la diversidad de debates y actualizaciones que los autores clásicos suscitan en torno a la acumulación originaria, nos parece fundamental subrayar la actualidad de este fenómeno y mostrar el lugar diferencial que las mujeres ocuparon en este proceso.
}

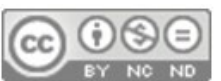


otro más importante aún, como índice del análisis del funcionamiento de la economía de mercado en relación con sus crisis repetidas periódicamente, que hacen, de la dinámica de la transformación, una continuidad.

Sin embargo, la terminología común da lugar a una discusión de la visión polanyiana trabajada en diversos puntos, que recorren la extensa historia del trabajo, abordada en la secuencia que va de la esclavitud al trabajo salariado (Moulier-Boutang,2006). La hipótesis principal del libro es trazar una genealogía de la constitución del mercado laboral capitalista, a partir de un eje fundamental: la movilidad de la fuerza de trabajo. La movilidad es entendida como fuga y ésta es considerada principio genético y definitorio de la constitución del mercado de trabajo asalariado. Pero esta historia se remonta más allá de los enclosures ingleses del siglo XVIII, retratados en el famoso capítulo XXIV de El capital, y busca situar sus inicios en una economía esclavista transatlántica impulsada desde el siglo XV. Será ese "activo específico" de la movilidad, como lo denomina Moulier-Boutang (2006), el que determinará progresivamente la relación dinero/trabajo y el que permitiera releer la acumulación originaria desde otra luz. Según esta lectura, la restricción de la movilidad de la fuerza de trabajo, así como las diversas formas de su regulación, se convierten en objetivo específico de todo el andamiaje de derechos (de propiedad, políticos, civiles y demográficos).

La perspectiva del movimiento -en términos de éxodo- de la mano de obra achaca la fuga, en primer lugar, a la resistencia al trabajo a convertirse en dependiente y a subordinarse como tal. Para este autor, la gran fijación de la mano de obra precedió a la gran transformación liberal que analiza Polanyi (2003). Este doble movimiento (fijación y transformación) obliga a complejizar el relato del inicio del capitalismo, mostrando la fuga como forma principal de resistencia. ${ }^{5}$

\section{La acumulación originaria: Descentrando los orígenes y poniendo el cuerpo}

Los inicios del capitalismo deben revisitarse una y otra vez desde el punto de vista de las mujeres que han estado, con demasiada frecuencia, ausentes en la historia del capitalismo. En este sentido, queremos poner el eje en la formación del cuerpo como cuerpo obediente y explotable; es decir, su constitución violenta como fuerza de trabajo. Por esto nos interesa el momento "originario" del capitalismo global: para recuperarlo como dinámica histórica de conflictos y modalidades de subordinación de la vitalidad humana a la lógica del capital. Nuestro énfasis estará puesto en el proceso diferenciado con que este disciplinamiento se impone a los cuerpos femeninos.

Pero para repensar esta escena de disciplinamiento, la escena "primitiva" de los cercamientos (enclosures) debemos ir más atrás de la época de la industrialización y más allá de Europa. Se trata de problematizar la idea de neutralidad de género en el

\footnotetext{
${ }^{5}$ Uno de los modos de regulación de la fuga es la caridad (o, lo que hoy llamaríamos, asistencia social); para Boutang, esto muestra la imposibilidad de fijación de la mano de obra. En este punto, nos centrarnos en los inicios de la modernidad capitalista, dado que las prácticas vinculadas a la caridad tal como se desarrollaron en sociedades antiguas y medievales estaban vinculadas a otras formas de relación social.
} 
relato de Polanyi (2003), Marx (2005) y Moulier-Boutang (2006). Hay diversas líneas de trabajo que proponen, actualmente, una reconceptualización de los usos de la noción de "acumulación originaria". Nos concentraremos en la perspectiva de Federici (2010), quien, por un lado, retoma esta discusión sobre la acumulación originaria vinculándola al cuerpo de las mujeres y los bienes comunales y, por otro, critica que la perspectiva de la fuga del trabajo planteada por Moulier-Boutang (2006) sea la única para pensar la resistencia a la subordinación, lo que permite dar una vuelta más a su crítica sobre la noción de trabajo libre.

Federici (2010), cuestiona este vector privilegiado de la huida y su propuesta de movilidad, como principio general de constitución de la fuerza de trabajo:

No fueron los trabajadores -mujeres u hombres- quienes fueron liberados por la privatización de la tierra. Lo que se 'liberó' fue el capital, ya que la tierra ahora estaba 'libre' para funcionar como medio de acumulación y explotación, ya no como medio de subsistencia. (p.103)

Esta crítica señala también el riesgo de no tener en cuenta a los sujetos que no se caracterizan por su movilidad, sino - por el contrario- por su imposibilidad de fugar, debido a una serie de vínculos de cuidado y de territorialidad que los fijan, de un modo u otro, a ciertos espacios y relaciones ${ }^{6}$. En el caso de las mujeres, son ellas quienes ven disminuidas sus capacidades de movilidad por estar ligadas a las tareas afectivo-reproductivas.

El poder de las mujeres, en lo que Segato (2010) llama el mundo aldea, muestra la existencia de un patriarcado, que si bien jerarquiza a las mujeres en desventaja, no impide la construcción de su política y formas de poder en relación con el dominio sobre la reproducción y el territorio.

Los vínculos exclusivos entre las mujeres, que orientaban a la reciprocidad y a la colaboración solidaria tanto ritual como en las faenas productivas y reproductivas, se ven dilacerados en el proceso del encapsulamiento de la domesticidad como vida privada. Esto significa, para el espacio doméstico y quienes lo habitan, nada más y nada menos que un desmoronamiento de su valor y munición política, es decir, de su capacidad de participación en las decisiones que afectan a toda la colectividad. Las consecuencias de esta ruptura de los vínculos entre las mujeres y del fin de las alianzas políticas que ellos permiten y propician para el frente femenino, fueron literalmente fatales para su seguridad, pues se hicieron progresivamente más vulnerables a la violencia

\footnotetext{
${ }^{6}$ A manera de ilustración, aunque no necesariamente en concordancia con el periodo observado por Federici, pero en ocasión del análisis de los orígenes "vale recordar que la resistencia de las mujeres a su esclavitud no sólo consistía en la fuga. Fueron quienes organizaron lo que se ha llamado "operaciones tortuga" en las casas grandes de los amos. Se trataba de operaciones de sabotaje y boicot: por ejemplo, el desperdicio de productos alimenticios, incluso su putrefacción, así como los abortos autoinducidos como forma de oposición a que sus hijos e hijas fueran esclavizados. Son estas conductas resistentes lo que la dominicana Celsa Albert (2003) denomina cimarronaje doméstico.
} 
masculina, a su vez potenciada por el estrés causado por la presión sobre ellos del mundo exterior. (Segato, 2010, p.18)

Queremos retomar y subrayar una clave que expone Federici (2012) y que se vuelve, para nosotras, fundamental en términos metodológicos y políticos: ¿en qué sentido la acumulación originaria se funda y se reitera sobre la expropiación de lo común?, y ¿cómo pensar lo común incluyendo la casa, el cuerpo y la tierra?

El trabajo de Federici (2012) muestra que no es posible entender la destrucción de estas sociedades orgánicas sin poner en primer plano la violencia social, política, económica e institucional que, mediante la caza de brujas, refundó las relaciones entre los géneros. La estigmatización de las mujeres implicó el despojo de su poder y estatus social asociado al dominio de sus capacidades reproductivas, a la autonomía en la resolución de sus necesidades de reproducción, a su participación en la esfera pública y a los conocimientos en el uso de plantas y tratamientos para la sanación de las enfermedades ${ }^{7}$.

Si bien hay acuerdo acerca de que en los sistemas sociales anteriores al capitalismo, el patriarcado también jerarquizaba lo masculino como superior a lo femenino, la existencia de bienes comunes y la desmercantilización dominante en las llamadas economías de subsistencia garantizaba mayores niveles de autonomía para las mujeres ${ }^{8}$. En estas sociedades, los saberes médicos eran una parte fundamental de la economía doméstica. Además, la ruptura entre naturaleza/cuerpo y civilización/razón no se había concretado; por tanto, la magia y la invocación a las fuerzas de la naturaleza era un saber común y necesario para garantizar las condiciones para la vida, y una fuente de poder para las mujeres que accedían a estos saberes ${ }^{9}$.

De hecho, es la organización patriarcal de las sociedades la que permite entender que la destrucción de la autonomía reproductiva, característica de estas economías campesinas, solo fue posible de ser concretada con la caza de brujas. El poder y el prestigio que las mujeres obtenían por su control sobre los procesos asociados al cuidado de la vida se veían amenazados por los cercamientos. Destruir este poder no solo implicaba tener la fuerza material para imponer el cercamiento de las tierras; también implicó desvertebrar las prácticas y creencias sociales acerca de lo que pueden o no hacer hombres y mujeres. La regulación del cuerpo femenino, con la instauración del capitalismo, implicó que las capacidades reproductivas y de trabajo quedaran expropiadas con el control del Estado

\footnotetext{
${ }^{7}$ Si consideramos el contexto social en el que se produjo la caza de brujas, el género, y la clase de los acusados y los efectos de la persecución podemos concluir que la caza de brujas en Europa fue un ataque a la resistencia que las mujeres opusieron a la difusión de las relaciones capitalistas y al poder que habían obtenido en virtud de su sexualidad, su control sobre la reproducción y su capacidad de curar", en Federici (2010, pp. 261-262).

${ }^{8}$ No pretendemos hacer una idealización del estatus de las mujeres previo al inicio de la modernidad capitalista, ni desconocer prácticas expropiatorias anteriores, propias de las épocas antigua y medieval (para lo cual los importantes volúmenes de M. Perrot y G. Duby constituyen una referencia ineludible), sino poner de relieve el capítulo específico de "la caza de brujas" como momento fundacional de un período particular.

${ }^{9}$ La relación entre la economía esclavista y las acusaciones de brujería como economía femenina autónoma están deliciosamente narradas en la novela de Marysé Conde: Yo, Tituba, la bruja negra de Salem, Fondo Editorial de Casa de las Américas, La Habana, 2010.
}

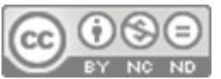


y del mercado en la forma de recursos económicos y, en última instancia, de los varones en su entorno más próximo. En este sentido Federici (2010), indica que los procesos de cercamiento y de persecución a las mujeres están interrelacionados:

En Irlanda y los Highlands occidentales de Escocia, no se encuentra ningún rastro de persecución, posiblemente porque en ambas regiones todavía predominase un sistema colectivo de tenencia de la tierra y lazos de parentesco que impidieron las divisiones comunales y el tipo de complicidad con el estado que hizo posible la caza de brujas. De esta manera- mientras-en los anglizados y privatizados Lowlands escoceses, donde la economía de subsistencia fue desapareciendo bajo el impact o de la reforma presbiteriana, la caza de brujas se cobró 4.000 víctimas, el equivalente al $1 \%$ de la población femenina en los Highlands y en Irlanda las mujeres estuvieron a salvo durante la caza de brujas de brujas. (p. 264)

Por tanto, en una economía en la que la subsistencia estaba garantizada por el acceso a la tierra y los saberes propios, se hacía necesario romper con la fuerza proveniente de las relaciones de parentesco y de vecindad. Un mecanismo funcional a este propósito consistió en la degradación de las mujeres y en la vaguedad de las acusaciones de brujería. Este hacía posible que cualquier mujer que desarrollara las prácticas habituales del mundo campesino pudiera ser llevada a juicio y que sus familiares fuesen obligados a pagar los largos y onerosos procesos.

Esto produjo un clima de terror generalizado y contribuyó a romper con los lazos de solidaridad comunitaria. La denigración de los saberes femeninos debilitó la capacidad de resistencia de las propias mujeres y de sus comunidades. El régimen de terror generado por la acusación de brujería produjo una parálisis social que hizo inviable muchos procesos de resistencia ante el despojo de la tierra. A la vez, creó un escenario de vulnerabilidad cultural que contribuyó a socavar y estigmatizar las formas de vida no capitalistas y, en particular, sus conocimientos y autonomía.

La erosión de la dignidad de las mujeres desplazó las tensiones sociales hacia lo femenino, compensando por esta vía la pérdida de estatus de los varones expulsados de sus tierras. Aquellas que vivían solas o en hogares sin presencia masculina, las que tenían mayor edad y, por tanto, más conocimientos sobre la interrupción de los embarazos, la atención del parto, etc., estaban más expuestas a las acusaciones, así como las clases sociales más pobres, quienes además tenían mayores razones para defender su acceso a la tierra.

Con esta argumentación, no pretendemos idealizar ni la sociedad pre-capitalista ni anular los procesos de subordinación de las mujeres que se daban en ellas. Nuestro énfasis se justifica en poner de relieve el momento de constitución del modo moderno de acumulación capitalista para subrayar los particulares mecanismos de despojo y expropiación que lo hicieron posible. 
Si bien los autores clásicos dan cuenta en los orígenes del capitalismo del proceso desplegado para convertir el cuerpo en instrumento de trabajo, no se diferenciaron los modos bajos los cuales este proceso tuvo connotaciones específicas para las mujeres. A partir de este proceso se instauró el confinamiento a una esfera doméstica como elemento fundamental de las nuevas relaciones de producción, el cual se fue constituyendo, en la medida en que el trabajo reproductivo perdía valor social y las mujeres, movilidad e independencia en el espacio público. Se reelaboró una división sexual del trabajo que garantizaba la dependencia femenina frente al Estado, el mercado y la familia.

La caza de brujas, entonces, puede leerse como un episodio central de la "guerra contra las mujeres" como manera de disciplinar, codificar y volver dócil el cuerpo femenino y, con él, consagrar el primer paso sobre la formación del cuerpo proletario como cuerpo obediente. Sin dejar de lado, por supuesto, la producción de los géneros como dinámica constitutiva de la división jerárquica y sexualmente diferenciada de la división global del trabajo.

\section{Analogía entre territorio y cuerpo femenino: su conversión en bienes comunes a ser expropiados}

No solo se trataba de socavar las condiciones necesarias para el desarrollo de formas de subsistencia autónoma: también era necesario construir un nuevo conjunto de significaciones acerca de la relación entre hombres y mujeres, y de cada uno de los géneros con la naturaleza.

Frente a la pérdida al acceso la tierra, para muchos varones la propiedad sobre el cuerpo femenino fue un lugar de resarcimiento de estatus. Este, en analogía a una nueva relación con la naturaleza, se fue constituyendo en un territorio para ser dominado. En el proceso de transición al capitalismo, la mayoría de la población estaba vinculada con la tierra. La racionalidad que acompañaba estas formas de vida no consideraba la escisión total entre seres humanos y naturaleza; la magia daba cuenta de esas formas de interrelación.

En los juicios de brujas se constituyó una naturaleza femenina en la que se subrayó su carácter sensual, corpóreo e instintivo para argumentar su inclinación a la perversidad y a sexualidades que escapaban del objetivo reproductivo. Se opusieron estos valores a la razón encarnada en los eruditos jueces de la iglesia que interrogaban y torturaban a estas mujeres campesinas con nociones completamente ajenas a sus formas de vida.

Se requirió de un proceso prolongado de estigmatización y persecución para que las mujeres perdieran el dominio sobre sí mismas, y el cuerpo femenino fuera territorializado y convertido en un lugar para la expresión de las relaciones de poder en todos los órdenes. La caza de brujas permite la enajenación del cuerpo, lo separa de la razón y facilita que este se convierta en un recurso regido por las relaciones de mercado, sustentado en un orden político patriarcal contractualista (Pateman, 1995).

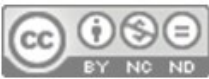


En coincidencia con los planteamientos del debate feminista de la década de los setenta, que analizaba la relación entre el trabajo doméstico y la economía política de la sociedad capitalista y, siguiendo en particular las tesis de James y Dalla (1977) y Federici (2010) sostienen que la desvalorización e invisibilización del trabajo de las mujeres lleva a la creación del trabajo doméstico como forma de separar tajantemente producción y reproducción y, de ese modo, se habilita un uso capitalista del salario para comandar el trabajo de los no asalariados. Federici, como anticipamos, direcciona la fuerza de este argumento para pensar esta desposesión del trabajo femenino como núcleo de la acumulación originaria del capitalismo.

En este sentido, plantea que ante la privatización de la tierra (enclosures) -núcleo más conocido en la teorización de la acumulación originaria- las mujeres devienen los "nuevos bienes comunes". Esto significa que su cuerpo y su trabajo son mistificados como servicio personal o recurso natural (o ambos). Un territorio del que se puede usufructuar en la medida en que garantiza la reproducción social y provee de servicios comunes, según (Federici, 2010):
De acuerdo a este nuevo contrato sexual, para los trabajadores varones las proletarias se convirtieron en lo que sustituyó a las tierras que perdieron con los cercamientos, su medio de reproducción más básico y un bien comunal del que cualquiera podía apropiarse y usar según su voluntad. Los ecos de esta 'apropiación primitiva' pueden oírse en el concepto de 'mujer común' (Karras, 1989) que en el siglo XVI calificaba a aquellas que se prostituían. Pero en la nueva organización del trabajo todas las mujeres (excepto las que habían sido privatizadas por los hombres burgueses) se convirtieron en bien comunal, pues una vez que las actividades de las mujeres fueron definidas como no-trabajo, el trabajo femenino comenzó a aparecer como un recurso natural, disponible para todos, no menos que el aire que respiramos o el agua que bebemos. (p.135)

La derrota histórica de las mujeres fue, en este sentido, la constitución de una esfera doméstica feminizada y devaluada ante el creciente prestigio de la esfera mercantil: por medio de un nuevo orden patriarcal, argumenta Federici (2010), se hizo cumplir la "apropiación primaria" masculina del trabajo femenino que implicó para las mujeres una "doble dependencia": de sus patrones y de los hombres. De este modo, la esclavización de las mujeres a la reproducción plantea, justamente, una analogía con las esclavas en América en un mismo movimiento del capitalismo en sus violentos inicios.

Esta violencia, lejos de suscribirse al momento iniciático del capitalismo, se renueva con la pulsión permanente para la apropiación de nuevos bienes y espacios comunes. Como contrapunto, nos interesa pensar los momentos de crisis como episodios donde la legitimidad de los cercamientos y el encapsulamiento de lo doméstico se ponen en juego. La crisis como momento de des-cercamiento: 2001 
Si bien se ha enfatizado en la mercantilización de la tierra, el trabajo y el dinero como condiciones fundamentales para la imposición del sistema de producción capital, quisimos remarcar el papel que el cuerpo y los saberes femeninos han tenido en estas formas de acumulación originaria. ¿Cómo plantear la actualidad de este proceso? ¿Cuáles son los modos a través de los cuales esto sigue ocurriendo, renovando las violencias de esa acumulación originaria?

Proponemos pensar desde un acontecimiento específico: la crisis argentina de 2001 -con su impacto a nivel continental- como un momento de des-cercamiento tras el impacto de las privatizaciones neoliberales. Por des-cercamiento queremos dar cuenta de un momento de apropiación colectiva de ciertos usos de bienes y servicios, impulsado por el momento excepcional de la crisis. Des-cercamiento tiene un sentido preciso: un momento de comunitarización o puesta en común de saberes y recursos que hacen posible desarrollar la vida en un momento marcado por la escasez y la fragilidad de los modos establecidos de reproducción social.

Sobre esta hipótesis, que exploraremos, es posible luego lanzar la pregunta por el modo en que la llamada "salida" de la crisis supone una nueva definición de bienes y recursos comunes (materiales e inmateriales) a ser explotados. Nos interesa puntualizar cómo nuevos cercamientos se ciernen sobre los ámbitos de la reproducción social y sobre los cuerpos y lugares de poder de las mujeres (y más ampliamente de una economía popular feminizada, es decir, asumida fuertemente por un protagonismo de mujeres).

El fracaso institucional que supuso la radicalización del orden mercantil profundizado mediante una década de reformas neoliberales en Argentina y la resistencia de los movimientos sociales produjeron "el 2001", una crisis inédita que implicó el derrumbe del monopolio del valor por la moneda y su comunitarización: por entonces convivieron, en el territorio nacional, más de una decena de monedas formales e informales, reconocidas por distintos niveles de autoridad estatal, provincial y municipal. La experiencia de 2001 como colapso implicó los más altos niveles de desocupación e índices de pobreza de la historia reciente, junto con la confiscación de los ahorros bancarios a los pequeños y medianos ahorristas. La impugnación al sistema político representativo fue radical (MTD de Solano y Colectivo Situaciones, 2002; Scribano y Schuster, 2001; Svampa y Pereyra, $\underline{2003)}$.

Como respuesta a la crisis, tal situación llevó a que muchas de las actividades de cuidado, que estaban en el marco de los hogares y particularmente de las mujeres, fueran llevadas a la resolución colectiva; los comedores comunitarios y las redes de trueque pronto fueron impregnados por las lógicas de la economía doméstica. En este periodo de fuerte crisis en los mercados, las redes populares de abastecimiento impactaron sobre la producción y la reproducción, organizando redes de intercambio y reciprocidad que solventaron la vida de millones de personas.

Lo reproductivo dejó de ser una responsabilidad de las familias, de lo privado, y se llevó a la esfera pública (Barrancos, 2013). Esta suspensión de la hegemonía capitalista 
$-y$, en particular, de su legitimidad como orden social- permitió la emergencia de otras economías que ya estaban presentes; pero que se encontraban arrinconadas por la expansión ilimitada de las relaciones de mercado, además de la reinvención de nuevas formas institucionales.

El momento de crisis produjo una desestabilización de la férrea división sexual del trabajo que propone el capitalismo y uno de cuyos componentes fundamentales es la consideración del ámbito reproductivo como un espacio que no hace parte de la economía. El mercado autorregulado perdió su capacidad de obliterar los demás procesos sociales, y la pérdida de credibilidad en las instituciones permitió la emergencia de nuevos espacios en todas las esferas de la vida.

El lugar que en estas prácticas tuvo lo doméstico, la construcción de formas de deliberación política que permitían la integración de la reproducción y la producción como un problema de la sociedad en su conjunto muestran la fuerza que, en la ciudad, tuvieron las prácticas de descercamiento vinculadas a la manera en cómo estas repusieron, en el paisaje urbano, espacios para lo público no estatal. La emergencia de prácticas que cuestionaron las formas en que la división sexual del trabajo hetero-normativa propone un capitalismo patriarcal que subraya la invisibilidad del trabajo doméstico como algo propio de la naturaleza femenina -y por tanto irrelevante- se vio interpelada por la urgente necesidad de construir una "economía que cuidara de la sociedad"10.

Si bien la configuración acerca del menor valor de lo femenino y las actividades a este campo adscritas constituye un núcleo duro de la subjetividad labrada por el sistema capitalista, este momento de crisis relajó los mecanismos sociales que garantizaban que el Estado y el mercado ubicaran lo reproductivo en la trastienda de la relaciones comunitarias, de parentesco y domésticas, desarrolladas de forma mayoritaria por las mujeres.

La diversidad de prácticas desplegadas en lo deliberativo y en la llamada economía social/popular(recuperación de fábricas, redes de trueque, cooperativas, autogestión del hábitat, servicios públicos, mercados solidarios, etc.) contribuyó a reinventar formas para resolver lo doméstico: la crisis desnudó su carácter eminentemente político y colectivo, dotándolo de un prestigio que favoreció la participación masculina de estos ámbitos, de modo tal que cuidar y garantizar la vida fue un trabajo que involucró a la mayor parte de la sociedad.

La crisis fue un momento donde el trabajo llamado doméstico (de cuidado, de alimentación, etc.) pasó a primer plano, porque se articuló de manera masiva con los subsidios al desempleo y, en muchos hogares, se convirtió en el único recurso capaz de proveer ingresos. Además, porque, desde entonces, ese protagonismo social en la crisis también dio lugar a un redimensionamiento político de la asistencia pública: la repartición de víveres, una tarea clásicamente doméstica, resultó fundamental en la formación de

\footnotetext{
${ }^{10}$ Para una discusión acerca del tránsito de una economía del cuidado a una economía que cuide de la sociedad, ver Quiroga, 2012.
} 
movimientos y emprendimientos que, en muchos casos, reivindicaron la independencia del estado, al apropiarse de sus recursos y re-direccionarlos, colectivamente, alterando su asignación individual. En 2001 la reproducción social logra altos niveles de autonomía respecto a las relaciones de empleo, mostrando, a su vez, cómo la noción de empleo se distancia de la producción (biopolítica) de valor social, capaz de sustentar formas de socialización en la crisis.

En sí, la organización barrial-territorial necesita de los saberes domésticos y, al mismo tiempo, los proyecta en un espacio público-político de manera muy especial cuando la crisis es simultáneamente crisis de la representación política y de la función mediadora de las instituciones en general (Gago, 2011). Esto supone, en la experiencia popular, una capacidad de reapropiación de un instrumento de gubernamentalidad que, desde su origen, representa el embate estatal contra formas alternativas de socialización para, luego de producir la desposesión, reestatizar lo social (Hirsch, 1996).

\section{¿Nuevos cercamientos?}

Nuestra hipótesis es que durante la crisis se produjo una feminización de la comprensión de la economía y, con ella, un activo descercamiento de los recursos para la reproducción. Con esto queremos decir que, a partir de la crisis, el estatuto del trabajo domésticoreproductivo entra en procesos de reconocimiento social y de valorización política de gran impacto. Así, se ponen límites al avance sobre las formas de acumulación originaria característica de la década de los noventa en su forma financiera y se avanzó sobre derechos y bienes sociales asociados a lo público.

Como señala Barrancos (2013):
A lo largo de los tiempos la visibilidad social y política de las mujeres se revela de modo imperioso como un emergente de crisis. La plurisecular imposición patriarcal- problema acerca del cual hoy contamos con un frondoso registro historiográfico-, ha inhibido a las mujeres de la participación en asuntos que conciernen a la res publica y les ha asignado el mandato de la reproducción y del cuidado doméstico, más allá de las circunstancias de lugar y de época que amenizan esta fórmula recalcitrante. (p. 2)

Esta feminización que remarcamos fuertemente asociada a la coyuntura de la crisis es efecto de la politización de la reproducción social impuesta por esa singular situación, la cual desnaturaliza su carácter subsidiario de la vida en común. En ese marco, los varones pudieron participar de la llamada economía doméstica con un reconocimiento social tras la pérdida en masa de miles de puestos de empleo. En la ciudad estas dinámicas producen una nueva espacialidad a través de lo público no estatal, la cual se puso de relieve como lugar decisivo de producción de valor social y fundamento de otro tipo de prácticas económicas.

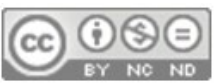


Nos queda la pregunta sobre si la salida de la crisis, a partir del discurso de la "vuelta del Estado" y la reposición de la legitimidad del sistema político como principal herramienta de tramitación de demandas a través de diversas formas de asistencia, vuelve a depreciar esa esfera y esos regímenes de autonomía capaz de negociar con las instituciones estatales, desde el reconocimiento de su función de productividad social y, sobre todo, de integración de lo doméstico y lo público mediante la creación de nuevos comunes.

Vale recordar que, desde sus orígenes, la asistencia pública fue: 1) un momento decisivo en la relación estatal entre trabajadores y capital, y en la definición de función del Estado; 2) el primer reconocimiento de insustentabilidad del sistema capitalista que rige por hambre y terror; 3) el primer paso en la reconstrucción del estado como garante de relaciones de clase, como supervisor de la reproducción y disciplinamiento de la fuerza de trabajo (Federici, 2010) ${ }^{11}$.

Ahora, lo que estamos discutiendo es la posibilidad de apropiación y de uso táctico de esos recursos que, en un principio, son distribuidos como asistencia social. En este sentido, lo que nos interesa recalcar es cómo se enhebra la asistencia pública con la capacidad de gestión de grupos que pujan por la comunitarización de los recursos de la reproducción y cuestionan el lugar de la asistencia como regulador de las relaciones entre el capital y el trabajo.

La ciudad reinventada en el 2001, a partir de una diversidad de prácticas de la economía popular y economía social, en las que lo reproductivo tomó un carácter directamente público, conjuga hoy nuevas lógicas de reconocimiento y de subordinación de esas dinámicas populares. Se pone en juego, de una manera ambivalente, lo común; es decir, una pluralidad de procesos de creación que va de lo material y físico a procesos inmateriales, afectivos e intelectuales. Queremos subrayar que lo común, entonces, no es un conjunto de bienes preexistentes, sino una dinámica popular de invención y reapropiación. Despliega una inteligencia para negociar con el Estado y, en ese punto, no plantea una autonomía ingenua, más bien se trata de propuestas que coexisten a la vez que contestan y tensionan la subjetividad patriarcal y la construcción del cuerpo heteronormativo inscrito en la división sexual del trabajo, en la naturalización de una economía mercadocéntrica y en una política instituida desde lo representativo.

En palabras de Gutiérrez (2013b):

. . a partir de un conjunto de acciones de lucha, las sociedades paulatinamente recuperaron y reconstruyeron capacidades políticas en el sentido más amplio: posibilidades de gestionar colectivamente lo que a todos incumbe porque a todos afecta. Eso tendencialmente erosionó y amenazó con disolver ciertos términos modernos de comprensión de lo político, como la distinción privado/público. Y la amenaza de disolución de esta añeja distinción, que funda una gran parte de nuestra comprensión de lo político pues los momentos de la lucha también

\footnotetext{
${ }^{11}$ Ver también, al respecto, Donzelot (1979), Policía de familias. Valencia: Pre-Textos.
} 
fueron tiempos enérgicos de producción y reproducción de lo común. Lo común no es una categoría clasificatoria que aluda a la propiedad sino que es una idea-fuerza central de la reorganización de la convivencia social. (“¿Qué significa el horizonte...”, párr. 1)

Por supuesto, no se trata de espacios exentos de incertidumbres y contradicciones. Precisamente el reconocimiento de estos dilemas muestra la manera en que la autogestión es, aún en estos contextos, capaz de la construcción de lo común y, por tanto, de limitar el inacabado proceso de acumulación originaria a la que apela -una y otra vez-el capitalismo.

Finalmente, nos interesa subrayar el modo en que esos espacios soportan las tensiones de géneros y las contradicciones vinculadas a una red de prácticas promiscuas, propias de una urbe abigarrada (Gutiérrez, 2013a). Consideramos, entonces, que la construcción de lo común dejó huellas en lo urbano, en la subjetividad social y en la ampliación de posibilidades para formular lo público más allá de lo estatal; que ese momento de descercamiento, como puesta en común de saberes y prácticas para la resolución de la vida, constituye un repertorio de experiencia fundamental, así como la perspectiva de una politización de la reproducción social.

De ahí que concluimos preguntándonos por la manera en que la tendencia a la mercantilización de esos espacios (por medio de una compleja dinámica de reconocimientos y capturas, de novedosos subsidios y modos del mercado laboral, etc.) es una marca de la acumulación originaria de esta época y también un signo de una nueva lógica del valor social, en la que el cuerpo femenino y-con él- la tierra, la casa y lo común quedan nuevamente en el centro de las disputas por su apropiación y explotación. 


\section{Referencias}

Barrancos, D. (2013). Mujeres y crisis en la Argentina: de las Madres de Plaza de Mayo a las piqueteras. En J. Lanes-Marsall, D. Marcilhacy, M. Ralle y M. Rodríguez (Eds.), Los conflictos en los mundos ibéricos e iberoamericanos contemporáneos, De las elaboraciones sociales y políticas a las construcciones simbólicas. (pp. ). Paris: Éditions Hispaniques. Manuscrito en prensa.

Benería, L. (1999). Mercados globales, género y el hombre de Davos. La Ventana, (10), 7-48. Ir a artículo http://148.202.18.157/sitios/publicacionesite/pperiod/ laventan/Ventana10/ventana10-1-1.pdf

Benería, L. (2005). Género, desarrollo y globalización. Por una ciencia económica para todas las personas. Barcelona: Editorial Hacer. Ir a libro http://www.hacereditorial.es/ webempresa_groc/catalegindex.php?idcat=30\&idprod=59\&vdetall=1

Benería, L. y Roldan, M. (1992). Las encrucijadas de clase y género. México: Fondo de cultura económica. Ir a libro http://books.google.co.cr/books/about/Las encrucijadas de clase y g\%C3\%A9nero.html?id=6FDaAAAAMAAJ\&redir esc=y

Butler, J. (2000). El marxismo y lo meramente cultural. New Left Review, 2, 109-121. Ir a artículo: http://newleftreview.es/article/download pdf?language=es\&id=1939

Delphy, C. (1977). The Main Enemy. Londres: Women's Research and Resource Center. Recuperado de http://webcache.googleusercontent.com/ search?q=cache:http://libcom.org/files/delphymainenemy.pdf

Chesnais, F. (2001). La mundialización financiera. Buenos Aires, Argentina: Losada. Ir a libro: $\underline{\text { http://www.editoriallosada.com.ar/masinfo.php?id=586\&coleccion=3 }}$

Federici, S. (2010). Calibán y la bruja. Mujeres, cuerpo y acumulación originaria. Argentina: Tinta Limón Ediciones. Ir a libro: http://tintalimon.com.ar/libro/CALIBN-Y-LABRUJA

Federici, S. (2012). Revolution at Point Zero Housework, Reproduction, and Feminist Struggle. Brooklyn, NY: PM Press. Ir a libro: https://secure.pmpress.org/index. php?|=product detail $\& p=420$

Folbre, N. (1982). Exploitation comes home: a critique of the Marxian theory of family labor. Cambridge Journal of Economics, 6, 317-392. http://cje.oxfordjournals. org/content/6/4/317.full.pdf+html 
Fraser, N. (2012). Reflexiones en torno a Polanyi y la actual crisis capitalista. Papeles de relaciones ecosociales y cambio global, 118, 13-28. Ir a artículo: http://www. fuhem.es/media/cdv/file/biblioteca/Analisis/2013/reflexiones sobre_Polany i y la actual crisis capitalista N.Fraser.pdf

Gago, V. (2011). Mutaciones en el trabajo en la Argentina post 2001: entre la feminización y el trabajo esclavo (Tesis de doctoral). Recuperado de SISBI http://catalogosuba. sisbi.uba.ar/tesis/index.php/record/view/609429

Gardiner, J., Harrison, J. y Seccombe, W. (1975). El ama de casa bajo el capitalismo. Barcelona: Anagrama. El Ama de Casa Bajo el Capitalismo. Recuperado de: http://books.google.co.cr/books/about/El_Ama_de_Casa_Bajo_el_Capitalismo. html?id=3IAYAAAACAAJ\&redir esc=y.

Gutiérrez, R. (2013a). Modernidades alternativas. Reciprocidad y formas comunitarias de reproducción material (mimeografiado). Manuscrito inédito.

Gutiérrez, R. (25 de junio, 2013b). Reconstruir el sentido común disidente. Página/12. Recuperado de: http://www.pagina12.com.ar/diario/ elmundo/4-222975-2013-06-25.html

Hartmann, H. (1981). The Unhappy Marriage of Marxism and Feminism: Toward a more Progressive Union. En Sargent, L. (Ed.), Women and Revolution: A Discussion of the Unhappy Marriage of Marxism and Feminism. Boston: South End Press. Ir a libro: http://www.amazon.com/Women-Revolution-Discussion-PoliticalControversies/dp/0896080617

Harvey, D. (2003). The New Imperialism. Estados Unidos: Oxford University Press. Ir a libro: http://ukcatalogue.oup.com/product/9780199264315.do

Hirsch, J. (1996). Globalización, Capital y Estado. México: UAM-X.

Humphries, J. (1977). The Working Class Family, Women's Liberation, and Class Struggle: The Case of Nineteenth Century British History. Review of Radical Political Economics, 9(3), 25-41. Ir a artículo: http://rrp.sagepub.com/content/9/3/25. full.pdf+html

James, S. y Dalla, M. (1977). El poder de la mujer y la subversión de la comunidad. Siglo Veintiuno.

Marazzi, C., Fumagalli, A, Lucarelli, S, Marazzi, C., Negri, T. y Mezzadra, S. (2009). La gran crisis de la economía global. Madrid: Traficantes de Sueños. Ir a libro: http:// www.traficantes.net/libros/la-gran-crisis-de-la-economia-global 
Marx, K. (2005). El Capital, Tomo I-1867. México: Siglo XXI.

MTD de Solano y Colectivo Situaciones. (2002). Hipótesis 891: Más allá de los piquetes. Buenos Aires: De mano en mano. Ir a libro: http://www.nodo50.org/ colectivosituaciones/pop up libro 03.htm

Nicole-Claude, M. (1991). L'Anatomiepolitique. Catégorisationsetidéologies du sexe. Paris: Côté-femmes. Ir a libro: http://www.editions-ixe.fr/content/lanatomie-politique

Molyneux, M. (1979). Beyond the domestic labour debate. New Left Review, 116

Moulier-Boutang, Y. (2006). De la esclavitud al trabajo asalariado. Madrid: Akal. Ir a libro: Ir a libro: http://www.akal.com/libros/De-la-esclavitud-al-trabajoasalariado/9788446019770

Pateman, C. (1995). El Contrato Sexual. Madrid: Anthropos.

Polanyi, K. (2003). La gran transformación. Los orígenes políticos y económicos de nuestro tiempo. Madrid: La Piqueta. Ir a libro: http://books.google.co.cr/books/about/ La gran transformaci\%C3\%B3n.html?id=bC9oAFNt9BQC\&redir esc=y

Quiroga-Díaz, N. (diciembre, 2012). Economía del cuidado. Retos para un feminismo decolonial. Revista Casa de la Mujer ,15(20). Recuperado de http://www.revistas. una.ac.cr/index.php/mujer/issue/current

Segato, R. (2010). Género y colonialidad: en busca de claves de lectura y de un vocabulario estratégico descolonial. En Quijano, A. y Mejía, J. (eds.), La cuestión descolonial. Lima: Universidad Ricardo Palma - Cátedra América Latina y la Colonialidad del Poder.

Scribano, A. y Schuster, F. (setiembre, 2001). La protesta social en la Argentina de 2001: entre la normalidad y la ruptura. OSAL Observatorio Social de América Latina, (5), 17-22. Ir a artículo: http://biblioteca.clacso.edu.ar/ar/libros/osal/osal5/analisis. pdf

Svampa, M. y Pereyra, S. (2003). Entre la ruta y el barrio. La experiencia de las organizaciones piqueteras. Buenos Aires: Biblos. Ir a libro: http://books.google.co.cr/books/ about/Entre la Ruta $y$ el Barrio.html?id=i79FAAAAYAAJ\&redir esc=y 
Natalia Quiroga Díaz, Verónica Gago

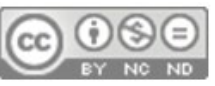

